when the male and female nuclei fuse, the zygote is not regarded as an embryo. This means that the prohibition of creating embryos for research does not apply to the first 20 hours. Dr Trounson and his colleagues at Monash University in Victoria have requested this amendment from the minister on the basis that the 20-hour gap will give them sufficient time to test whether micro-injection of deficient sperm into the egg results in a chromosomally defective zygote.

Based on these tests, Trounson and his colleagues plan to go ahead and insert micro-injected eggs into the uterus of infertile women (or of fertile women in the case of infertile partners). Indeed, they have already done this earlier this year. As the law stands, the insertion of microinjected eggs into the uterus of a patient in an IVF programme is not regarded as research, and hence does not need the approval of the Victorian IVF review committee. It is assumed that premature work would be stopped by the local bioethics committee. In the micro-injection case just mentioned this had not happened and so the work had gone ahead.

Clearly embryo research laws are very difficult to formulate in such a way that they encapsulate all that a parliament may wish to have regulated. It is hoped that the less than satisfactory legal situation in Victoria will serve Britain as a useful lesson for how not to draft such legislation.

DitTta BARTEls School of Science \& Technology Studies, The University of New South Wales, PO Box 1, Kensington,

New South Wales, Australia 2033

\section{German angle}

SIR-The leading article regarding the Embryo Protection Law being formulated by the West German Justice Ministry (Nature 333, 787; 1988) was loaded with subjective comments, which are indeed matters of opinion and not incontrovertible. To take them in order:

It is indeed a "paradox that research should be singled out" for this legislation. Clearly this does not prove that the legislation is unnecessary. It may just need to be extended in scope.

- Our understanding of the ethical implications of medical research lags far behind our technological progress. A degree in biochemistry is not a qualification in moral philosophy, and the idea that researchers should or can "police themselves" is ill-founded at best, especially as profit, prestige and prizes are available to motivate those who break the rules.

- I disagree that it is small consolation to the research community for "history and the legal system" to provide restraint to scientific research. Civilized society must look to the mistakes of the past and protect itself from making the same mistakes in the future. Research in a society devoid of such constraints would be intolerable.

The article concludes by implying that the West German people should "appreciate that embryo research may, in due course ... rid people of undignifying genetic diseases". We are a long way from curing anyone of a genetic disease, but have already begun ridding ourselves of PEOPLE, with what we consider "undignifying genetic diseases", through abortion and euthanasia. How similar that sounds to the rationale used by the Nazis to attempt the genocide of the Jewish race.

It is my sincere hope that generations to come will not have cause to condemn us for crimes which they view in the same way as we now view the crimes of Nazi Germany.

Kenneth W. M. Cochran AT\&T Bell Laboratories,

200 Laurel Avenue,

Middletown,

New Jersey 07748, USA

\section{Moratorium call}

SIR-We read with deep concern the letter by Braude et al. (Nature 332, 459-460; 1988) regarding the activation of the human embryonic genome. We feel that in this study the ethical bounds of scientific work have been overstepped.

Although biologists have developed techniques to manipulate mammalian embryos, the abuse of these techniques through experiments with human embryos (or pre-embryos, if one considers a preimplantation embryo not to be an embryo) must be condemned by the scientific community. Scientists cannot wait for public or political pressure to define the limits of their work. The time has come for an Asilomar-type moratorium to establish ethical boundaries for work on human embryos.

In our opinion this study is unethical. We think therefore that experiments of this kind should not be encouraged by their publication in any journal, including Nature.

(This letter represents the views of the undersigned senior scientists or graduate students, and should not be construed as necessarily representative of the views of the institute or the society for which we work.)

Rudi Balling, Kamal Chowdhury,

Urban Deutsch, Susanne Dietrich, UWE Drescher, UlF HENSEling,

Birgit Jostes, Gunnar-Ingi

Kristuansson, Tine de Maeyer, Andreas Püschel, Hans Schöler, Daria Siekhaus, Franz Theuring, Claudia Walther, Andreas Zimmer

Department of Cell Biology,

Max-Planck-Institute of Biophysical Chemistry,

Göttingen, FRG

\section{Conservation plan}

SIR-I was interested in your leading article (Nature 333, 284; 1988) outlining the problem of OECD food subsidies.

A possible useful way of harnessing the excess production would be to give or sell the food to developing countries at a reduced rate in return for land/forest conservation programmes. A scheme involving third world debt/conservation exchange seems to be working well.

The idea has a lot going for it. For example, the OECD farmers would be working for the retention of the remaining virgin land on this planet instead of purely for government hand-outs.

25 Avenue Athol,

R. G. H. CotTon

Canterbury,

Victoria 3126, Australia

\section{New OSHA standards}

SIR-You report (Nature 333, 590; 1988) that OSHA has set new permissible exposure limits for more than 400 chemicals. In fact, the agency has proposed new limits.

We are currently holding hearings on the proposal which should be completed by mid-August. We hope to issue a final standard for these chemicals before the end of the year.

Akio Konoshima

US Department of Labor,

Occupational Safety and Health

Administration,

Washington, DC 20210, USA

\section{Ozone layer}

SiR-Why not pressurize spray-cans with ozone?

14 Salisbury Court,

Salisbury Avenue,

London N3 $3 A H, U K$

\section{Cover blown}

SIR-Wordsworth wrote: "Little we see in Nature that is ours". Indeed, the picture appearing on the cover of the issue of 7 July, attributed to us, is not our work.

Arthur M. Lesk VICTOR I. LESK

\section{Field Way, Cambridge, UK}

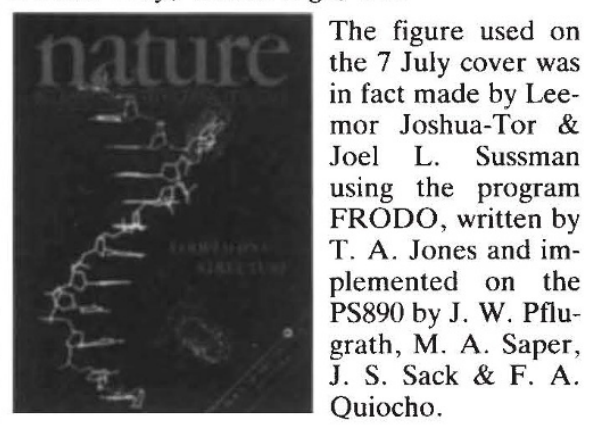

